\title{
MARXISMO E CRÍTICA LITERÁRIA
}

MARXISM AND LITERARY CRITICISM

\author{
Adriana Jesuíno Francisco ${ }^{1}$ \\ Vicentônio Regis do Nascimento Silva ${ }^{2}$
}

EAGLETON, Terry. Marxismo e crítica literária. São Paulo: Editora Unesp, 2011, 160 p.

Escrever bem é mais do que uma questão de "estilo"; significa também ter à disposição uma perspectiva ideológica que possa penetrar nas realidades da experiência dos homens em uma dada situação. (p. 23)

Livro de agradável diagramação que exige concentração do leitor, Marxismo $e$ crítica literária sistematiza quatro campos de reflexões: as relações entre Literatura e História, as aproximações entre Forma e Conteúdo, o engajamento do escritor e, por fim, a equiparação do autor a mero produtor no mercado capitalista. Desde os primeiros contatos, Eagleton enfatiza que a crítica marxista não constitui apenas sociologia adicional ao campo hermenêutico, mas uma tentativa de explicar plenamente a obra literária, considerando formas, estilos e significados como produtos específicos de uma História, sempre caracterizada por três fatores: a) Base ou Infraestrutura (em que sobressai o caráter econômico); b) Superestrutura (formas jurídicas e políticas que legitimam o poder dos detentores dos meios de produção econômica); c) Ideologia (habilita as ideias dominantes, provenientes da classe dominante, na sociedade).

A arte para o marxismo faz, assim, parte da "superestrutura” da sociedade. Ela faz parte (...) da ideologia de uma sociedade - um elemento nessa complexa estrutura de percepção social que garante que a situação em que uma classe social tem poder sobre as outras seja vista pela maioria dos membros da sociedade como "natural", ou que nem seja vista. Entender a literatura significa, então, entender todo o processo social do qual ela faz parte. Como observou o crítico marxista russo Georgi Plekhanov: “A mentalidade social de uma época é condicionada pelas relações sociais dessa época. Não há outro lugar em que isso fica mais evidente do que na História da Arte e da Literatura”. (p.19)

\footnotetext{
${ }^{1}$ Graduanda em Letras pela Universidade Estadual Paulista Júlio de Mesquita Filho (UNESP), câmpus Assis. Email: drimouse@yahoo.com.br

${ }^{2}$ Doutorando em Letras pela Universidade Estadual de Londrina (UEL). Mestre em História pela Universidade Estadual Paulista Júlio de Mesquita Filho (UNESP), câmpus Assis. E-mail: vicrenos@yahoo.com.br
} 
Os homens não escolhem suas relações sociais. Restringem-se a elas em decorrência da necessidade material. Além do enredo e da caracterização, o crítico literário - e, na mesma condição, o estudante de letras - precisa compreender a complexidade - aproximações e contradições - da ideologia, refletindo, em termos mais abrangentes, a História contemporânea. A obra literária atinge a universalidade ao substituir o sentimentalismo local por termos cosmopolitas, conceituados em “(...) parte de uma condição humana imutável”. (p.35) Local ou universal, as obras de arte não estão inteiramente livres de conteúdos ideológicos de maneira que o capítulo seguinte dedica-se a esmiuçar as relações entre Forma e Conteúdo.

Segundo Eagleton, os críticos marxistas acreditam na relação dialética entre Forma e Conteúdo, ressaltando que este precede aquela e, em último caso, Conteúdo sobrepõe-se à Forma, definida em cada situação histórica. “As formas são determinadas historicamente pelo tipo de ‘conteúdo’ que elas devem incorporar; elas são alteradas, transformadas, demolidas e revolucionadas à medida que o conteúdo muda”. (p. 46)

\begin{abstract}
Dada essa visão tão limitada da relação entre forma e conteúdo, não surpreende constatar que os críticos marxistas ingleses da década de 1930 com frequência cometiam o erro do "marxismo vulgar" de pilhar as obras literárias em busca de seu conteúdo ideológico, relacionando-o diretamente à luta de classes ou à economia. Era contra esse perigo que o comentário de Lukács tinha o objetivo de nos advertir: os verdadeiros condutores da ideologia na arte são as formas da própria obra, não o conteúdo que delas podemos abstrair. Encontramos a marca da história na obra literária precisamente como literária, não como qualquer forma superior de documentação social. (p.50)
\end{abstract}

Avanços significativos na Forma promovem mudanças na ideologia, abrindo os olhos às novas percepções de realidade social e às relações entre o artista e o público. Detentora de alto grau de autonomia, a Forma não se submete às instabilidades ideológicas, contudo estabelece unidade complexa constituída de três elementos: moldagem nas formas “relativamente autônomas”, cristalização a partir de estruturas ideológicas dominantes e personificação das relações entre autor e público. Independente do gênio pessoal do escritor, a recriação atrela-se à ideologia do momento histórico e ao seu posicionamento dentro da história.

Embasado na tríade Totalidade, Tipicidade e Histórico Universal - conceitos menos marxistas do que hegelianos - Lukács define o grande artista como capaz de recapturar e recriar a totalidade da vida humana por meio de detalhes concretos do cotidiano. Em semelhante linha de pensamento, Engels conceituará genuíno o personagem que congrega 
Tipicidade e Individualidade citando, como exemplos, Balzac e Shakespeare que, embora tachados de conservadores, aglutinam ambas as características. Lukács retoma Engels acrescentando que, para construção tipicamente individualizada, o escritor deve ser progressista a ponto de dramatizar o personagem. A dramatização de personagem mostrar-seia ineficaz tanto no Naturalismo quanto no Formalismo.

O Naturalismo é uma espécie de esvaziamento do significado e da direção da história em decorrência da distorção do realismo: em vez de descrever de maneira profunda, registra passivamente o mundo capitalista degradado, reproduzindo, de maneira fotográfica, os fenômenos superficiais da sociedade, realçando os traços típicos e consolidando visão alienada da sociedade em que o escritor não é participante ativo da história, mas mero observador clínico. Por sua vez, o Formalismo - exemplificado por nomes como Kafka, Musil, Joyce, Beckett e Camus - despe o homem de sua história, internalizando-se em seu próprio eu, fugindo de qualquer outra realidade, aprisionando os personagens em caos mentais. A realidade, no Formalismo, é um caos ininteligível.

Discípulo de Lukács, Lucien Goldmann debruça-se sobre o texto literário com a finalidade de investigar a estrutura de pensamento ou “visão de mundo” do grupo a que o escritor pertence.

\footnotetext{
Quanto mais o texto se aproxima de uma elaboração completa e coerente da "visão de mundo" da classe social, maior é a sua validade como obra de arte. Para Goldmann, as obras literárias não devem ser vistas, em primeiro lugar, como a criação de indivíduos, mas sim daquilo que ele chama de "estruturas mentais transindividuais" de um grupo social - ou seja, a estrutura de ideias, valores e aspirações que esse grupo compartilha. Os grandes escritores são aqueles indivíduos excepcionais que conseguem transpor para a arte a visão de mundo da classe ou do grupo a que pertencem, e que fazem isso de uma forma peculiarmente unificada e transparente (mesmo que não necessariamente consciente). (p.63-64)
}

Goldmann batiza esse método crítico de Estruturalismo Genético. Estruturalismo por se interessar pelas estruturas de categorias; Genético, pelos percursos pelos quais essas estruturas mentais são produzidas historicamente. Busca um conjunto de relações entre texto literário, visão de mundo e história, mostrando como a situação histórica de um grupo é transposta para a obra literária através de uma visão de mundo. Inspirado em conceito hegeliano de consciência social, o modelo de Goldmann não acomoda os conflitos dialéticos, nem abrange as irregularidades e descontinuidades das relações entre Literatura e Sociedade. 
Para Pierre Macherey, uma obra vincula-se à ideologia pelos silêncios. O crítico literário deve coagir os silêncios da obra - sempre descentralizada e de significados conflitantes - à fala, à oralidade, à verbalização, ao discurso.

O terceiro capítulo - aborda o engajamento do escritor - salienta, na Rússia pósrevolucionária, a instalação do Proletkult, espécie de laboratório com finalidade de criar cultura puramente proletária e sem influência burguesa, respaldado por escritores que, por meio de seus romances, glorificariam o maquinário comunista, alicerçando, dessa maneira, o que viria a ser chamado de Realismo Socialista. O bom escritor fornece o retrato do progresso revolucionário defendendo, em sua arte, os interesses do partido. Embora partilhe da concepção, Trotski assimila a forma artística como produto de conteúdo social com alto grau de autonomia. Outros críticos - predecessores de Marx - já pregavam a Literatura como fonte de análise e crítica social, encaixando o artista, no caso, o escritor, na condição de “esclarecedor social”.

Em cartas, Engels esclarece que o escritor não pode seguir o Naturalismo transformando-se em mero fotógrafo, inativo observador - mas se dedicar ao realismo, enfocando a realidade por meio do drama sem, no entanto, utilizar excessivamente o melodrama. Os personagens não podem ser superficiais nem distantes da realidade. A boa obra conjuga duas características aparentemente contraditórias: intenção subjetiva e significado objetivo. O Princípio da Contradição, na representação literária, aparentemente ressalta oposições que, na prática, não existem. O bom escritor - assegura Engels - domina os mecanismos relativos e aplica as técnicas absolutas.

Para os adeptos da teoria reflexionista, a obra literária relaciona-se ao mundo real, pressupondo o reflexo ou a reprodução da realidade social de maneira razoavelmente direta. Segundo Lukács, a consciência é uma força ativa, uma intervenção criativa e, portanto, não constituiria mero reflexo. Macherey defende o efeito deformador - distanciando-se da imitação - da Literatura que, por sua vez, tem a função de parodiar, eliminando a possibilidade da simples cópia dos acontecimentos. Os escritores modernos - argumenta Lukács - devem apresentar perspectivas críticas sobre o desespero e a insatisfação da sociedade burguesa, apontando outras possibilidades às futilidades consumadas.

O último capítulo desmistifica a aura romântica atribuída aos escritores ao inseri-los na categoria de produtores subordinados ao sistema capitalista. Questionando a posição da obra literária dentro das relações produtivas de sua época, Walter Benjamim define a função 
do artista/escritor revolucionário: a arte depende de certas técnicas produtivas que integram as relações sociais entre o produtor artístico e seu público.

\begin{abstract}
(...) o artista revolucionário não deve aceitar de modo indiscriminado as forças de produção artística existentes, mas sim desenvolver e revolucionar tais forças. Ao fazer isso, ele cria novas relações sociais entre o artista e o público; ele supera a contradição que limita as forças artísticas, potencialmente disponíveis a todos, à propriedade privada de poucos. Cinema, rádio, fotografia, gravações musicais: a tarefa do artista revolucionário é desenvolver essas novas mídias, assim como transformar os modos mais antigos de produção artística. Não se trata apenas de promover uma "mensagem" revolucionária por meio de mídias existentes; a questão aqui é revolucionar as próprias mídias. (...) O artista verdadeiramente revolucionário, portanto, nunca se ocupa apenas com o objeto artístico, mas com os meios da sua produção. $\mathrm{O}$ "engajamento" não se limita à apresentação de opiniões políticas corretas pela arte; ele se revela no grau em que o artista reconstrói as formas artísticas à sua disposição, transformando autores, leitores e espectadores em colaboradores. (p. 111-112)
\end{abstract}

A transformação de autores, leitores e espectadores em colaboradores acontece por meio de choques, caracterizados pelas colisões de sensações fragmentadas e descontínuas. De acordo com Walter Benjamim, Bertolt Brecht exemplificaria essa teoria através de críticas aos efeitos da alienação estampadas em suas peças em que a arte revolucionária transforma os modos - e não só o conteúdo - da produção artística.

De maneira geral, ao longo de Marxismo e crítica literária Eagleton reflete sobre três aspectos inter-relacionados: 1) Os novos significados atribuídos à ideia de forma artística (tanto Brecht quanto Benjamim ponderam sobre as relações produtivas entre artista e público); 2) Redefinição do conceito de autor (para Benjamim e Brecht, o escritor não é um criador, figura romântica e mística, mas um produtor como qualquer produtor, por exemplo, de móveis, de casas, de carros); 3) Redefinição de produto artístico (Lukács acredita que a arte recria a totalidade e a harmonia ao superar as alienações representadas pelas contradições capitalistas entre essência e aparência, concreto e abstrato, individual e todo social; Brecht julga reacionária a proposta de Lukács, opondo-se a ela e sugerindo a exposição dessas contradições, estimulando os homens a aboli-las na vida real).

Adeptos ou arredios, adoradores ou avessos ao marxismo precisam inteirar-se das possibilidades dessa corrente crítica que não é, nas palavras de Eagleton, uma técnica alternativa de interpretação, mas uma teoria cujos fundamentos - base, superestrutura, arte, produção, ideologia - precisam, assim como em qualquer outra teoria, ser (re)enfrentados pelas gerações atuais de críticos, especialmente os marxistas. 